\title{
Artigo
}

\section{A questão dos riscos e o acordo SPS}

\author{
The matter of risks and the SPS agreement \\ DOI: 10.5752/P.1809-6182.2016v13.n3.p179
}

Camila Gontijo $^{1}$

\section{RESUMO}

Recebido em: 23 de fevereiro de 2016 Aprovado em: 25 de maio de 2016

O tema do risco que surge na sociologia e na teoria jurídica é analisado na sua aplicação no Acordo de Medidas Sanitárias e Fitossanitárias da OMC. A partir do Acordo SPS, e de sua análise sobre os artigos referentes ao tema risco, as disputas no Órgão de Solução de Controvérsias da OMC são analisadas sob o aspecto de sua constituição. A relação entre os Estados envolvidos gera a conclusão de que há o uso do risco como forma de protecionismo, ao se verificar a formação das disputas nessa arena que tem como principais atores os Estados Unidos e a Comunidade Europeia.

Palavras-chave: Organização Mundial do Comércio. Acordo de medidas sanitárias e fitossanitárias. Riscos. Disputas.

\section{ABSTRACT}

The risk matter is analyzed first on sociology and then on law theory. In this article the risk is analyzed in the view of the WTO Sanitary and Phytosanitary Agreement. The disputes in the Dispute Settlement Body are analyzed considering the SPS Agreement and its articles referring to the risk theme. The relation among the implicated States on disputes is the main point to the conclusion about the United States and the European Community as the main actors using the risk as protectionism.

Key words: World Trade Organization. Sanitary and Phytosanitary Agreement. Risk. Disputes.

1. Mestre em Direito das Relaçôes Internacionais, UniCeub; MBA em Gerenciamento de Projetos, FGV; Bacharel em Relaçóes Internacionais, PUC-MG. Experiência em negociaçóes internacionais, monitoramento de acordos internacionais, internacionalização, inteligência de mercado, projetos para desenvolvimento da indústria brasileira. ORCID: orcid.org/0000-0003-3206-6613. 


\section{Introdução}

A questão dos riscos é discutida em diversos âmbitos e em diversas áreas do conhecimento, apresentando variadas caracterizações e possibilidades de ocorrência que podem gerar danos a um indivíduo ou a toda uma coletividade. No âmbito do direito a consideração do risco é diferente em cada área, como no direito ambiental, no direito econômico, no direito dos investimentos, por exemplo. A jurisdiçâo de cada país, e cada tratado internacional que considere esse tema apresentarão também a sua própria definição de risco.

$\mathrm{Na}$ área do direito internacional e das relações comerciais internacionais, há diferentes nuances que implicam riscos, como o transporte, a transação comercial, ou até mesmo a qualidade da mercadoria, para citarmos alguns tipos de riscos. Dessas possibilidades, esses e outros tipos de riscos são previstos nos acordos internacionais, assim como a maneira de contorná-los.

A partir do entendimento do que seria considerado risco pelos teóricos da sociologia e do direito, e do texto do Acordo sobre a Aplicação de Medidas Sanitárias e Fitossanitárias ${ }^{2}$ (SPS) da Organização Mundial do Comércio (OMC), poderemos analisar como o fator risco é usado para suspender as transaçôes comerciais entre dois Estados, ou entre um Estado e um grupo de Estados. Nesse enfoque, os riscos são trabalhados levando em consideração situações que possam prejudicar de alguma forma a saúde humana, animal ou vegetal, estando relacionados a processos produtivos ou os produtos finais.

Teóricos que tratam do tema, como por exemplo, Ulrich Beck (2010), afirmam que os Estados em desenvolvimento sofrem com riscos no ambiente internacional. No âmbito do comércio internacional, Estados desenvolvidos afirmam que os

2. Em forma resumida: Acordo de medidas sanitárias e fitossanitárias. produtos provenientes dos Estados em desenvolvimento apresentariam riscos seja à saúde de quem os consumisse ou como disseminador de algum tipo de contaminação. Dessa forma no comércio internacional, pode-se observar as diversas disputas que já ocorreram na OMC devido a barreiras impostas predominantemente por Estados desenvolvidos a produtos importados, aplicadas sob o pretexto desses produtos apresentarem riscos e embasadas na proteção da saúde da população nacional.

O embate entre a percepção do risco no comércio internacional, e sua expressão relacionada ao Acordo de Medidas Sanitárias e Fitossanitárias será analisado neste artigo a partir da análise das disputas estabelecidas no Órgão de Solução de Controvérsias (OSC) da OMC. Com isso, poderá se verificar se há uma relação de uso do fator risco como imposição de barreira comercial entre Estados desenvolvidos e Estados em desenvolvimento, ou algum outro tipo de relação entre as partes envolvidas nas disputas.

Para essa análise, perpassaremos por diferentes definiçōes de riscos formuladas pelos principais teóricos que tratam do tema, alguns usos, e organizaçôes internacionais. Em seguida apresentamos o Acordo de Medidas Sanitárias e Fitossanitárias da OMC e seus conceitos de risco, assim como o uso desses como tema para barreiras comerciais que tenham gerado controvérsias apresentadas à organização. Por fim, realiza-se um estudo de casos sob os artigos do SPS relacionados ao tema "risco" no sistema de solução de disputas da OMC, para verificação do nível de desenvolvimento dos Estados envolvidos e a formaçáo de barreiras comerciais.

\section{Definição de riscos}

O vocábulo "risco" pode apresentar diferentes definições conforme a área em que esteja aplicado. Como por exemplo, em economia, biotecnologia, 
esportes, direito, em cada área os aspectos e o escopo do que pode ter aplicada a noção de risco são diferentes. A percepção sobre os riscos e suas consequências também são amplamente variáveis conforme o tema aplicado. Neste artigo, vamos trabalhar com a questão de risco no ambiente do direito internacional, e do comércio internacional.

A definição de "risco" no campo da sociologia ou do direito tem algumas variaçóes conforme o teórico que o define, ou sistema jurídico no caso do direito. Vejamos então, como o "risco" é definido.

\section{Riscos e seus teóricos}

Os riscos podem ser definidos de diferentes maneiras conforme a área de aplicação e o entendimento dos estudiosos sobre o tema. O "risco", segundo Adam e Loon (2000), é aquilo que constrói uma incerteza que pode causar danos à vida, ou que pode acontecer. Loon ainda trata do termo risco, numa classificação de risco virtual, que seria aquele que nunca é real nesse sentido, mas que apresenta a possibilidade de se tornar real.

Esses mesmos autores, citando $\mathrm{Beck}^{3}$ apresentam uma noção de sociedade de risco e sua definição de sociedade de risco:

[...]condiçôes sociais, econômicas, políticas e culturais que são caracterizadas pela crescente incerteza disseminada da lógica da manufatura e implica na transformação das estruturas sociais existentes, instituições e relações para a incorporação de mais complexidade, contingência e fragmentação ${ }^{4}$ (ADAM; LOON, 2000, p.5).

Essa transformação nas instituições a qual é citada por Beck, vai se materializar, por exemplo,

\footnotetext{
3. Ulrich Beck foi um sociólogo alemão com obras de influência para política e direito, e criador do conceito de "sociedade do risco".

4. Tradução livre: "[...] social, economic, political and cultural conditions that are characterized by the increasingly pervasive logic of manufactured uncertainty and entail the transformation of existing social structures, institutions and relationships towards an incorporation of more complexity, contingency and fragmentation". (p. 5)
}

no estabelecimento das regras de prevenção dos riscos, como será tratado mais adiante ao se analisar as regras do acordo de Medidas Sanitárias e Fitossanitárias da OMC.

No âmbito jurídico da análise e definição de riscos, Kaye (2008) usa como exemplo a jurisdiçáo alemã que demonstra o uso da palavra "risco" naquele Estado, onde a lei civil teria mudado o entendimento de responsabilidade baseada em uma falta, para responsabilidade baseada em risco. $\mathrm{O}$ critério de base em risco seria referente ao fato de que uma atividade de risco poder ser repreensível, o que segundo o autor, leva ao entendimento de que o risco é um fato da sociedade de risco, enquanto as atividades envolvem açôes novas. Na Alemanha, a responsabilidade baseada no risco complementaria, segundo Kaye a responsabilidade baseada na falta.

Outro autor alemão, Niklas Luhmann ${ }^{5}$ citado por Kaye, afirma que "o conceito de risco se refere a possibilidade de dano atribuível a decisão de alguém, enquanto a incerteza descreve a possibilidade de dano causado por uma fonte externa ${ }^{(3)}$ (KAYE, 2008, p. 11).

A subjetividade e a objetividade sobre o risco é uma questão tratada por Kaye, a partir da determinação se o risco realmente existe, e o nível do risco (se aumentou ou diminuiu). Avaliaçôes qualitativas do risco podem ser feitas objetivamente, e a lei contribui para estabelecer os níveis aceitáveis de risco para proteger a sociedade.

O’Malley (2009) afirma que o risco envolve a referência a técnicas de incerteza, e nas teorias contemporâneas, o risco é definido como o oposto de incerteza, citando vários autores. Entre os autores citados, Maynard Keynes e Frank Knight defini-

5. LUHMANN, N. Verständigung über risiken und gefahren, Die politische Meinung, 1991, vol. 4.

6. Traduçâo livre: “...the concept of risk refers to the possibility of injury attributable to one's own decision, whereas a hazard describes the possibility of harm caused by an external source". (p. 11) 
ram risco como prediçóes, e incerteza como formas sistemáticas para se organizar a predição, acrescentando ainda que a incerteza surge do julgamento profissional, previsóes ou experiência.

Aplicando-se o conceito de risco no ambiente internacional encontra-se a análise feita por Beck em relação ao nível de desenvolvimento de um Estado, e a distribuição de riscos no sistema internacional. No primeiro capítulo do livro "Sociedade de risco" de Ulrich Beck, o autor trata do tema dos riscos relacionados a organização da sociedade, o que ele delimita como a distribuição da riqueza para fazer referência a países e regiōes com diferentes níveis de desenvolvimento.

No referido capítulo, Beck trata da questão de que indústrias poluidoras são transferidas de países com maior desenvolvimento para as regióes menos favorecidas. Essa movimentação das unidades fabris se deu principalmente na segunda metade do século $\mathrm{XX}$, com governos de Estados em desenvolvimento aplicando políticas de atração de investimentos extrangeiros visando o desenvolvimento local, sem considerar o potencial de riscos das atividades dessas empresas ou fatores ambientais, o que não gerava exigências quanto à segurança ambiental. A distribuição de riqueza no mundo, segundo Beck, seria inversamente proporcional à distribuição dos riscos ambientais e riscos diretos à saúde humana, ou seja, os Estados menos desenvolvidos ou em desenvolvimento, arcariam com os maiores riscos à medida que possuíssem mais indústrias poluidoras ou com alto potencial de acidentes.

Na mesma linha, Guzman (2007) afirma que os Estados mais pobres estariam mais dispostos a arcar com riscos para sua população, como por exemplo, aceitando a comercialização de produtos que apresentariam riscos. Além da comercialização, esses Estados receberiam as unidades produtoras, como no Brasil, onde o governo militar incentivou

\footnotetext{
7. Ten years of WTO dispute settlement, p. 226.
}

a instalação de empresas estrangeiras manufatureiras no país entre as décadas de 50 e 70 . Essa atração de empresas sem os devidos cuidados em relação aos seus riscos, levou a presença de alguns problemas, como por exemplo no caso do município de Cubatấo no estado de São Paulo. Conhecida pela poluição e acidentes ambientais, a cidade recebeu diversas empresas multinacionais estrangeiras com incentivos do governo brasileiro para sua instalação, cujas atividades acabaram prejudicando o meio ambiente e a saúde da população da região ${ }^{8}$ causando inclusive alguns acidentes.

A situação de risco é tratada por Beck, em cinco teses para o que ele denomina auto ameaça civilizatória. A primeira delas é relacionada a produção dos riscos no estágio mais avançado das forças produtivas, o que seria dependente da definição de riscos para os efeitos decorrentes de substâncias derivadas dos processos de produção, ou da instalação desses processos. A segunda tese é a de situaçôes sociais de ameaça que surgem a partir da distribuição e incrementos dos riscos, o que o autor relaciona ao que ele denomina como "novos desníveis internacionais" no processo de industrialização dos Estados em desenvolvimento. Outra tese é a de que "a sociedade industrial produz as situaçóes de ameaça e o potencial político da sociedade de risco"', num ambiente em que os riscos fossem parte da economia. A quarta tese de Beck é a de que as apesar do acesso a riquezas, os riscos decorrentes da sua produção afetam os seres humanos ao mesmo tempo, em que são atribuídos ao desenvolvimento da civilizaçâao. E por fim, a tese de que os riscos socialmente conhecidos apresentam um papel político para discussão na esfera pública.

Os autores estudados, como pôde ser observado, trabalham a noção de risco para a sociedade, e

8. Informaçóes sobre a situação da favela Vila Parisi, em Cubatão em: Beck (2010, p.51-52).

9. BECK, 2010, p. 28. 
como as decisóes sobre quem arcará com os riscos são tomadas, principalmente em relações políticas e de poder, e os diferentes tipos de riscos. Apesar de alguns autores fazerem um cotraponto entre risco e incerteza, nem todos tratam a diferenciação desses termos, o que pode-se inferir que para esses a incerteza também poderia apresentar um risco.

\section{Risco, precaução, e a $O M C$}

Para se analisar como a questão do risco é tratada na análise jurídica, é importante também entender a sua relação com o princípio da precaução. Quando há falta de informação em relação a determinado fato ou tema, a lei pode atuar com base no "princípio da precaução ${ }^{10 "}$, o qual segundo a definição da Conferência de Wingspread ${ }^{11}$ significa: Quando uma atividade ameaça ou fere a saúde humana ou o meio ambiente, medidas de precaução devem ser tomadas mesmo se a relação entre a causa e o efeito não estejam totalmente estabelecidas cientificamente ${ }^{12}$.

O princípio da precaução se reflete nos parágrafos do artigo 5 do acordo SPS, o qual se refere às questôes de riscos. Goldstein e Carruth (2004) chamam a atençáo para o uso do princípio da precaução como barreira comercial a partir de ações baseadas no risco, ou na precaução sobre a possibilidade de risco ${ }^{13}$. Algumas disputas na OMC seriam abertas com base nos artigos do SPS que tratam dos

10. O princípio da precauçấo foi proposto formalmente na Conferência Rio 92, Declaraçáo do Rio sobre Meio Ambiente e Desenvolvimento. Princípio 15, “[...] o princípio da precauçáo deverá ser amplamente observado pelos Estados, de acordo com suas capacidades. Quando houver ameaça de danos graves ou irreversíveis, a ausência de certeza científica absoluta não será utilizada como razão para o adiamento de medidas economicamente viáveis para prevenir a degradação ambiental".

11. Conferência de Wingspread sobre o Princípio da Precaução ocorrida em janeiro de 1998, na Fundaçáo Johnson em Wingspread, Estados Unidos.

12. Tradução livre: When an activity raises threat of harm to human health or the environment, precautionary measures should be taken even if some cause and effect relationships are not fully established scientifically.

13. (GOLDSTEIN; CARRUTH, 2004, p. 492.) riscos, mas com as defesas dos Estados demandados embasadas no princípio da precaução para justificar as práticas utilizadas (causando barreiras ao comércio) as quais foram geradoras da discussão.

A precaução é um tema de debate sobre a atividade da OMC, tendo alguns teóricos, afirmado que as diferenças culturais poderiam implicar em diferentes percepçôes e, portanto a interpretaçôes situacionais diferentes para a aplicação de alguma medida de precauçáo. A diferença de percepção de risco de uma cultura para outra também é ressaltada por Gruszcynski (2008), que inclusive relaciona esse fato ao nível de proteçáo adequado, definido por cada ator. Para Prazeres (2003), a utilizaçáo de medidas embasadas na precaução poderia deixar dúvidas para a sua caracterização como protecionismo, ainda mais por se definir como atos em momentos de "incerteza, indefinição ou desconhecimento da ciência sobre os riscos de determinada prática” (PRAZERES, 2003, p. 235). Isso poderia ser interpretado, pela adoção de medidas de precaução não seguirem os mesmos critérios de análise de riscos, que as medidas embasadas em "riscos".

As organizaçóes internacionais podem ter em seu tratado constitutivo ou nos acordos que a compóem, a apresentação de uma definição de risco aplicada a sua área de atuação. Nesse artigo será analisada principalmente a definiçáo de risco pela Organização Mundial do Comércio, mas o tema risco também é bastante considerado em outras áreas como a do meio ambiente, defesa e saúde, estando presente nas disussóes das organizaçóes internacionais responsáveis.

A sociedade através da OMC busca minimizar os efeitos dos riscos, assim como Beck defendeu em sua obra de que a sociedade do risco seria baseada na soluçấo de questốes como a minimização, dramatização e direcionamento. A organização é utilizada então como arena para a discussão do alcance 
e da determinação dos riscos que são enfocados em seus casos de disputas, e na revisão de seus acordos.

Para Beck, a sociedade de risco não está definida politicamente, mas é algo que ultrapassa fronteiras, tendo diferentes povos compartilhando os mesmos problemas. Nessa situação a solidariedade que existe no ambiente internacional não é somente para se fazer o bem, mas pelo contrário, é para se controlar e evitar que o pior aconteça. A partir dessa tese do autor, podemos fazer uma inferência sobre os motivos que podem ter embasado a OMC na construção dos seus acordos, e principalmente o que vamos analisar, o Acordo sobre Medidas Sanitárias e Fitossanitárias que trata amplamente do tema risco.

O conceito de risco está relacionado ao de precaução como visto anteriormente, sendo utilizado nos textos dos acordos ou na interpretação de casos concretos. As medidas de precaução sendo adotadas ou requisitadas além do conceito de risco são embasadas na possibilidade de haver alguma situação que implique risco a uma pessoa, grupo ou à natureza. Esse cenário de risco será visto nas próximas seçóes, no âmbito da OMC e do acordo em análise nesse artigo.

\section{OMC e SPS - riscos como tema de borreiras}

O Acordo SPS é um dos acordos que compóem a base jurídica da $\mathrm{OMC}$, sendo importante entendermos essa composição de acordos para se chegar ao ponto de estudo deste artigo. No estabelecimento da OMC, em 1995, houve a conformação jurídica contendo diversos acordos, organizados em seus anexos. No anexo 01 houve a incorporação do Acordo Geral de Comércio e Tarifas (GATT), acordo vigente desde 1947, com a incorporação de diversos acordos específicos, e novos acordos adotados como anexos ao acordo principal. $\mathrm{O}$ anexo
02 trata do entendimento de resoluçáo de disputas; o anexo 03 é relativo ao mecanismo de revisão de política comercial, e o anexo 04 engloba os acordos de comércio plurilaterais.

O objetivo do Acordo SPS foi a incorporação dos aspectos relacionados a medidas não tarifárias, especificamente as medidas sanitárias e fitossanitárias, que poderiam afetar o comércio entre os Estados, além de garantir a utilização dessas medidas nos casos em que fosse necessário para a proteção da vida e da saúde humana, animal ou vegetal. Dessa forma, o acordo SPS determinaria as condiçōes de aplicação das medidas sanitárias e fitossanitárias, para que não fossem utilizadas pelos Estados como barreiras ao comércio de forma protecionista.

A utilização de argumentos relacionados a riscos sanitários e fitossanitários para limitar o comércio internacional, foi reconhecido como um fator de extrema importância nas questôes comerciais e que levava a indisposiçóes entre as partes. A preocupação com os aspectos sanitários também foi um ponto de atenção no século XX pelo desenvolvimento dos métodos de produção de alimentos, estudos científicos sobre a nocividade de diversas substâncias e o questionamento do consumidor sobre a qualidade dos produtos industrializados, ou que sofriam a ação de qualquer outro produto durante o seu cultivo ou produção.

Nesse cenário de desenvolvimento tecnológico, o acordo veio para garantir aos Estados membros a possibilidade de aplicar certas medidas, e minimizar os efeitos negativos ao comércio derivados dessas medidas. Pode-se inferir que a aplicação desse acordo também garantiria em certo nível a proteçáo dos consumidores, o que se verá em algumas disputas na OMC. Os próprios Estados partes alegam ao tomar certas medidas, que essas são para a proteçấo de seus nacionais; o que precisa ser analisado em cada caso sob a ótica do acordo SPS e da real existência de um risco. 
Os Estados em desenvolvimento foram lembrados no texto do acordo, especialmente no cuidado nas análises de determinados fatos levando em consideração o impacto econômico, e os custos em se adotar métodos alternativos às possíveis barreiras impostas. O artigo 10, sobre tratamento especial e diferenciado, faz essa referência específica aos Estados menos desenvolvidos. No caso do estabelecimento de novos níveis de proteção sanitária ou fitossanitária, a adequação pode se dar em prazos mais longos para garantir as exportaçóes nesses Estados, como previsto nesse dispositivo.

\section{Cooperação e outras organizaçóes}

O funcionamento do acordo de medidas sanitárias e fitossanitárias e sua aplicação são defendidos pelo Comitê para Medidas Sanitárias e Fitossanitárias, o qual funciona sob o Conselho do Comércio de Bens da OMC.

$\mathrm{Na} \mathrm{OMC}$, o Comitê para Medidas Sanitárias e Fitossanitárias promove um espaço de discussão para cooperação, coordenação e harmonização, com decisóes tomadas por consenso. Além dessa articulação com os Estados membros, o comitê é responsável pelo relacionamento com as outras instituiçóes que tem temas convergentes e atuam em conjunto com a OMC para esse tipo de questâo, como o Codex Alimentarius, por exemplo.

$\mathrm{O}$ acordo SPS prevê a harmonização das medidas e o trabalho conjunto com instituições internacionais de referência para o estabelecimento de padrôes. A comissão de medidas sanitárias e fitossanitárias é responsável pela articulação institucional para a harmonização internacional. A instituiçâo de referência para alimentos é a Codex Alimentarius, a qual está atualmente sob a administração da Organização Mundial da Saúde (OMS) e da Organizaçáo para Alimentos e Agricultura das Nações Unidas (FAO).

O Codex Alimentarius, no seu Manual de Procedimentos, define risco como "uma função da probabilidade de um efeito nocivo para a saúde e da gravidade desse efeito, como consequência de um perigo proveniente dos alimentos" ${ }^{14}$. As análises de risco pelo Codex Alimentarius devem seguir três componentes, que são a avaliação, o gerenciamento e a comunicaçáo do risco ${ }^{15}$, os quais devem ser documentados de forma sistemática e transparente. A caracterização do risco irá indicar as estimativas de ocorrência e seus potenciais efeitos, além do tipo de perigo possível.

Outras instituiçóes que dão suporte à $\mathrm{OMC}$ em relação a segurança animal é a Organização Mundial para a Saúde Animal (IOE) ${ }^{16}$, e para questôes fitossanitárias e controle de pragas, a Convenção Internacional para a Proteção de Plantas (IPPC) ${ }^{17}$. Além da possibilidade que a OMC tem de usar normas e diretivas internacionais como referência.

A IOE trabalha com segurança alimentar e saúde animal, sendo referência na área sanitária, mas não apresenta uma definiçẫo para o termo "risco". A IPPC no texto da sua convenção de $1997^{18}$, também não trata de uma definição para o termo "risco" em si, mas apresenta as possibilidades de "análise de risco de pragas", "risco de pragas", e no modelo de certificado fitossanitário para reexportação está presente a expressão "risco de infestação ou infecção".

14. Tradução livre, de: "a function of the probability of an adverse health effect and the severity of that effect, consequential to a hazard in food".

15. Seção IV, Análise de riscos; Manual de procedimentos da Comissão do Codex.

16. A Organização Mundial para a Saúde Animal é referência para 45 organizaçóes além da OMC, e surgiu do Office International des Epizooties - IOE o qual foi criado em 1924. As principais atribuiçôes da organização são informar os Estados sobre doenças em animais, coordenar pesquisas sobre a cura e controle das epidemias, e harmonizar a legislação sobre a saúde animal.

17. IPPC, Convençáo Internacional para a Proteção das Plantas, é responsável pela análise da proteção das espécies silvestres, controle de pragas, desenvolve e divulga padróes internacionais, informaçôes e dá suporte a organizaçôes internacionais.

18. Ver artigos: 2.1, 4.2, 7.2, e 8.1. 
Além da cooperaçáo com a OMC de outras organizaçôes internacionais, o acordo SPS prevê assim como o Acordo de Barreiras Técnicas ao Comércio (TBT) o reconhecimento mútuo de medidas e padrôes de outros Estados, em seu artigo 4: "Os membros aceitarão como equivalente as medidas sanitárias ou fitossanitárias de outros membros, mesmo quando diferem das suas próprias ou das utilizadas por outros Membros que comercializem o mesmo produto,..” (Art 4.1).

\section{Avaliaçâo dos riscos e medidas}

$\mathrm{O}$ artigo 5 do Anexo A, do acordo SPS, afirma que as medidas adotadas devem ser tão extensas quanto forem necessárias para a proteção da saúde humana, animal ou das plantas ${ }^{19}$. A proporção de uma medida está relacionada à evidência científica do risco, ou comprovação dos riscos à saúde. O acordo SPS também encoraja os Estados membros a desenvolverem normas e estabelecerem a harmonização de parâmetros de reconhecimento internacional.

A avaliação do risco, segundo o Anexo A, do acordo SPS, significa:

Avaliação da probabilidade da entrada, erradicação ou propagação de pragas ou enfermidades no território de um Membro importador segundo as medidas sanitárias ou fitossanitárias que possam ser aplicadas, assim como as possíveis consequências biológicas e econômicas conexas; ou avaliação dos possíveis efeitos prejudiciais para a saúde das pessoas e dos animais pela presença de aditivos, contaminantes, toxinas ou organismos patogênicos nos produtos alimentícios, bebidas ou raçôes. (Acordo SPS, 1994)

A partir da determinação da avaliação do risco, entende-se que o risco segundo o acordo de medidas sanitárias e fitossanitárias corresponde a dois

19. SPS, Anexo A, art. 5 - Nivel adecuado de protección sanitaria o fitosanitaria - nivel de protección que estime adecuado el Miembro que establezca la medida sanitaria o fitosanitaria para proteger la vida o la salud de las personas y de los animales o para preservar los vegetales en su territorio. pontos. Na definição do acordo para a avaliação do risco, observa-se que o primeiro ponto de avaliaçáo é a entrada no Estado importador de corpos que podem ser contaminadores ou que provoquem a erradicação de seres vivos nesse Estado. E o segundo ponto, a análise de alimentos e bebidas. Ou seja, trata-se aqui do risco na possibilidade de contaminação e do produto já contaminado.

A determinação dos riscos e sua avaliação são realizadas pelos Estados internamente, o que levaria segundo Gruszczynski (2008), a alguns problemas derivados da própria regulaçáo do governo. A intervenção do governo se daria por uma estrutura regulatória de resposta aos riscos composta de análise, gerenciamento e comunicação de riscos. A análise ou avaliação dos riscos se inicia com o apontamento dos problemas potenciais, e em seguida o gerenciamento do risco implementa o processo de identificação, avaliação e ações para a redução dos riscos. A avaliação do risco é determinante para o estabelecimento do nível apropriado de proteção a ser $\operatorname{adotado}^{20}$. A última etapa desse processo é a comunicação do risco, para a informação dos fatos aos interessados, e incluído no processo para julgamentos e decisões quando em pauta de discussão na OMC ou outra arena.

As teorias sobre riscos citadas abordam a questão do risco para a sociedade, mas sem definir em que área ou aspecto específico estaria esse risco, sendo entendido a partir da maior parte das teorias de que se trata de riscos à vida, ou riscos às condiçóes do meio ambiente. Ao analisarmos o acordo SPS, encontra-se além da preocupação com os seres vivos, a questáo do risco econômico, ou seja, como certas medidas podem afetar não só as transaçôes comerciais, mas a economia de um determinado Estado.

Medidas que não sejam cobertas pelo acordo SPS em relação à proteção da vida humana, animal ou vegetal provavelmente serão pelo acordo TBT, ou

20. Da sigla em inglês: ALOP - appropriate level of protection. 
mesmo pelo texto geral do GATT. No artigo 1 do texto do SPS há a afirmação de que o acordo é aplicável a todas as medidas que possam afetar diretamente ou indiretamente o comércio internacional ${ }^{21}$ e de que nenhuma medida afetaria os direitos estabelecidos pelo acordo TBT ${ }^{22}$. Os limites do acordo SPS estão estabelecidos em seu Anexo A, que apresenta as definiçôes para a aplicação das medidas sanitárias e fitossanitárias, em seu artigo 1, alíneas a-d.

O anexo A, do SPS, art. 1, alínea a, trata da saúde dos animais e preservação dos vegetais em relação a doenças e pragas, a alínea b, discorre sobre a proteção da vida das pessoas e animais em relação a produtos alimentícios que possam se contaminar, enquanto as alíneas c e d tratam da entrada, erradicação e propagação de doenças ou pragas.

A avaliação dos riscos presentes no artigo 5 do acordo SPS - Avaliação dos riscos e determinaçáo do nível adequado de proteção sanitária e fitossanitária, apresenta em seus três primeiros parágrafos a avaliação dos riscos pelos Estados membros. A avaliação deve ocorrer conforme as técnicas de organizaçóes internacionais competentes, e considerando:

[...] os testemunhos científicos existentes; os processos e métodos de produçáo pertinentes; os métodos pertinentes de inspeçāo, amostragem e prova; a prevalência de doenças ou pragas concretas; a existência de zonas livres de pragas ou doenças; as condiçôes ecológicas e ambientais pertinentes; regimes de quarentena e outros. (Art. 5.2 Acordo SPS, 1994)

A avaliaçấo do risco e das medidas a serem aplicadas para a preservaçáo da saúde, da vida e dos vegetais, deve segundo o Art. 5.3 considerar também fatores econômicos:

21. SPS, Art. 1, parág. 1 - El presente Acuerdo es aplicable a todas las medidas sanitarias y fitosanitarias que puedan afectar, directa o indirectamente, al comercio internacional. [...]

22. SPS, Art. 1, parág. 4 - Ninguna disposición del presente Acuerdo afectará a los derechos que correspondan a los Miembros en virtud del Acuerdo sobre Obstáculos Técnicos al Comercio con respecto a las medidas no comprendidas en el ámbito del presente Acuerdo. [...]o possível prejuízo ou perda de produção ou de vendas em caso de entrada, erradicação ou propagaçáo de uma praga ou doença; os custos de controle ou erradicação no território do Membro importador; e a relação custo-eficácia de outros possíveis métodos para limitar os riscos. (Acordo SPS, 1994)

A aplicação de medidas relacionadas ao acordo SPS deve se pautar em três condiçóes estabelecidas pelo próprio acordo e ressaltado por $\operatorname{Stoll}^{23}(2006)$ : as medidas devem ser embasadas no risco, especificação dos elementos de não discriminação, e regras das medidas preventivas conforme as condiçóes do Art. 5.7 do acordo SPS.

As medidas somente devem ser aplicadas se for verificado a possibilidade de risco à saúde humana, animal e vegetal, e que sejam medidas que estejam em conformidade com os procedimentos homologados pelas organizações internacionais relevantes, citadas anteriormente. A questáo da evidência científica é um ponto primordial a ser considerado na aplicação de qualquer medida sanitária ou fitossanitária, a qual parte da análise de processos e métodos de produção, testes e checagens de produtos, para a verificação de contaminação. A análise e declaração de áreas livres de certas enfermidades ou pestes também é possível dentro do acordo SPS. O uso de produtos e técnicas também são levadas em consideração deixando aberta a verificação científica de novas técnicas e produtos e suas possíveis consequências de combinaçóes não existentes à época do estabelecimento do acordo.

Além da evidência científica, o acordo prevê a possibilidade de risco como critério na aplicação das medidas sanitárias e fitossanitárias. Admitindo-se que há evidência científica e risco para a saúde, o Estado membro deve determinar um nível de proteção proporcional $^{24}$ ao cenário estabelecido. Segundo o

23. STOLL, 2006, p. 143.

24. SPS, Art. 5 - Avaliação de riscos e determinação do nível adequado de proteçấo sanitária e fitossanitária. 
artigo 5.4, "ao determinar o nível adequado de proteção sanitária ou fitossanitária, os Membros deverão considerar o objetivo de reduzir ao mínimo os efeitos negativos sobre o comércio". O parágrafo seguinte evidencia a importância de se evitar diferentes níveis de proteção em diferentes situaçóes para que não haja discriminação. Stoll ressalta que a congruência entre os parágrafos 5.4 e 5.5 do acordo SPS reforçam a consistência política, o que não haveria se dependesse somente das legislaçôes nacionais.

A possibilidade de se aplicar medidas preventivas também é coberta pelo acordo, estando no parágrafo 5.7 presente essa possibilidade durante um tempo razoável para que os Estados levantem pesquisas e informaçóes adicionais. Esse tipo de medida se enquadra no princípio da precaução, o qual é comumente utilizado nos âmbitos do meio ambiente e da proteção do consumidor, como bem ressalta Stoll.

\section{Casos - estados em desenvolvimento apresentam riscos?}

$\mathrm{O}$ uso dos artigos referentes ao tema risco no Acordo de Medidas Sanitárias e Fitossanitárias é presente em diversas disputas no âmbito do Órgão de Solução de Controvérsias da OMC. Vários Estados Membros alegaram a existência de risco, ou negaram a afirmativa de outro Estado de que o produto importado seria proveniente de área de risco. A partir disso, serão anallisadas em seus aspectos gerais, as disputas na OMC sob o acordo SPS que envolveram o tema do risco.

\section{O sistema de solução de disputas na $O M C$}

A Organização Mundial do Comércio tem seu próprio mecanismo para resolução de disputas, o que a torna única em relação a esse tema e em comparaçáo com outras organizaçóes internacio- nais. A presença desse mecanismo garante um certo nível de neutralidade e igualdade entre os Estados partes numa disputa, pois não dependem somente de seus próprios meios diplomáticos para se chegar a uma resolução, mas terão suas questôes analisadas pela organização.

No processo de resolução de disputas na OMC, embasado pelo Entendimento relativo a Normas e Procedimentos sobre Solução de Controvérsias $(\mathrm{ESC})^{25}$ possibilita a solicitação de consulta, no qual pode haver ou não um entendimento entre as partes. Se não houver um entendimento na consulta, então um painel de especialistas é estabelecido, o que é também conhecido simplesmente como "painel". A resolução de disputas na OMC é baseada em várias regras, sendo formada pelo o que Stoll chama de "sistema integrado de resolução de disputas" o que leva a uma análise conjunta do $\mathrm{ESC}^{26} \mathrm{e}$ as regras constantes nos acordos da OMC. O Entendimento sobre solução de controvérsias trata das disputas sob qualquer assunto e acordo da OMC, ou seja, sobre bens, serviços e propriedade intelectual.

Os objetivos do órgáo de soluçáo de controvérsias da OMC segundo o artigo 3 do ESC são a resoluçấo de disputas em si, a proteçấo de direitos e obrigaçóes recíprocas e o esclarecimento de provisóes existentes conjuntamente às regras do direito internacional costumeiro em relação a tratados. $\mathrm{O}$ mesmo artigo ainda chama atenção para o fato de que o órgão não deve acrescentar ou diminuir o direito dos Estados partes envolvidos nas disputas. A resolução de um painel, de acordo com o artigo 17 , somente será bloqueada em caso de um consenso negativo, ou seja, todos os membros da OMC devem concordar em negar a resolução.

25. O ESC em sua forma resumida - Entendimento sobre solução de controvérsias do inglês Dispute Settlement Understanding (DSU) - foi aprovado durante o Encontro de Marraqueche, em 1994, ao final da Rodada Uruguai.

26. O ESC trata das questóes de procedimento para painéis de especialistas e órgão de apelação, para os casos sob as regras da OMC. 
O acordo SPS prevê a existência de painéis no âmbito do ESC, onde a resolução das disputas, se fará por painéis de especialistas e participação de instituiçóes para a resolução de questôes técnicas e científicas.

A resolução de uma controvérsia, segundo Jackson (2002), pode seguir duas técnicas com orientaçôes diferentes, a diplomacia orientada pelo poder, e a diplomacia orientada pelas regras. Essas orientaçôes se definem pela "resolução através de negociação e acordo com referência (explícita ou implícita) ao $s t a-$ tus relativo de poder das partes, ou resolução através de negociação ou decisão com referência a normas ou regras às quais ambas as partes tenham acordado previamente" ${ }^{27}$. Jackson ainda ressalta que nas duas técnicas, a negociação e a resolução de disputas são os mecanismos utilizados, mas devem-se observar os pontos usados para barganha.

A composição dos painéis, segundo o artigo 8 do ESC, exige a participação de pessoas que sejam bem qualificadas, podendo ser ligadas ou não ao governo. Esses participantes podem ter participado como representantes de seus países em várias instâncias da OMC, mas esses especialistas, também chamados de peritos, não podem ser nacionais de nenhuma das partes envolvidas no caso, mesmo nos casos em que seu país de origem esteja como terceira parte no painel. Os painéis são formados por três especialistas, ou cinco, se as partes assim indicarem. $\mathrm{O}$ inciso 10 do artigo 8, ainda garante que em casos entre Estados desenvolvidos e Estados em desenvolvimento, o segundo pode indicar que se tenha um especialista proveniente de um Estado em desenvolvimento membro da OMC no painel.

A revisão de um painel também está prevista pelo ESC, e dá a possibilidade de se consultar um

27. Tradução livre de: "[...] settlement by negotiation and agreement with reference (explicitly or implicitly) to relative power status of the parties; or settlement by negotiation or decision with reference to norms or rules to which both parties have previously agreed". (JACKSON, 2002, p. 109) especialista em casos de questóes científicas ou técnicas específicas para se obter uma opinião sobre o caso. Nesses casos, o painel pode requisitar um relatório do grupo de especialistas de revisão ${ }^{28}$. Mesmo com a composição técnica de um painel, pode haver discordâncias na interpretação das evidências pelos especialistas, algo que Guzman chama atenção ao se analisar que os painéis e o órgão de apelação seriam dependentes dessa avaliação.

$\mathrm{Na}$ prática, a aplicação de medidas e a análise dos painéis sobre os casos podem encontrar situaçôes as quais não estejam previstas nas normas. Guzman chama a atenção para o fato de que o órgão de solução de controvérsias deveria ter certa relativização ao se avaliar cada caso. Assim, o OSC deveria considerar o nível de risco que um determinado Estado está disposto a tolerar, os dados científicos, e a relação entre as medidas a serem adotadas ou que foram adotadas e a avaliação de risco prevista pelo acordo SPS.

\section{Disputas envolvendo o SPS - riscos}

O acordo SPS esteve presente como tema de 42 disputas incluindo pedidos de consulta e painéis entre 1995 e 2014, sendo que em 18 deles houve a referência aos artigos 5.1, 5.2 e 5.3 do acordo, os quais são referentes a avaliação do risco e determinação do nível adequado de proteção sanitária e fitossanitária. Abaixo, apresenta-se o texto dos referidos artigos.

\section{Artigo 5.1:}

Os Membros assegurarão que suas medidas sanitárias e fitossanitárias são embasadas em uma avaliação adequada às circunstâncias, dos riscos à vida ou à saúde humana, animal ou vegetal, tomando em consideração as técnicas para avaliação de risco elaboradas pelas organizaçôes internacionais competentes.

28. Previsto no artigo 13 - Direito de busca de informaçóes, do ESC. 
No artigo 5.1 vemos a relação à vida das pessoas, animais e plantas, e a responsabilidade da avaliação do risco por organizaçóes internacionais. Isso demonstra que náo é a OMC a responsável por determinar como os riscos devem ser avaliados, mas as organizações especializadas nos temas. Já no artigo 5.2 são apontadas as questôes básicas para a avaliação dos riscos.

Artigo 5.2:

$\mathrm{Na}$ avaliação de riscos, os Membros levarão em consideração a evidência científica disponível; os processos e métodos de produção pertinentes; os métodos para teste, amostragem e inspeção pertinentes; a prevalência de pragas e doenças específicas; a existência de áreas livres de pragas ou doenças; condições ambientais e ecológicas pertinentes; e os regimes de quarentena ou outros.

O terceiro artigo analisado, o 5.3, trata da relação econômica na avaliação dos riscos e medidas adotadas para a proteção sanitária ou fitossanitária. Neste artigo há a relação mais próxima para os efeitos que uma medida sanitária ou fitossanitária podem ter no comércio internacional e na economia interna dos Estados afetados.

\section{Artigo 5.3:}

Ao avaliar o risco para a vida ou saúde humana, animal ou vegetal e ao determinar a medida a ser aplicada para se alcançar o nível adequado de proteção sanitária ou fitossanitária para tal risco, os Membros levarão em consideração como fatores econômicos relevantes: o dano potencial em termos de perda de produçáo ou de vendas no caso de entrada, estabelecimento e disseminaçáo de uma peste ou doença; os custos de controle e erradicação no território do Membro importador; e a relação custo-benefício de enfoques alternativos para limitar os riscos.

Em relação ao artigo 5.1 ocorreram desde a criação da OMC até o ano de 2014, 17 casos, citando o artigo 5.2 foram 13 casos, e sobre o artigo
5.3 foram 6 casos, sendo que alguns casos fizeram menção a mais de um artigo referente a riscos. $\mathrm{O}$ primeiro caso sobre o tema foi no ano 2000, entre Estados Unidos e México, o caso DS 203 - Medidas afetando a comercialização de suínos vivos. Resumidamente os painéis por parágrafo do artigo 5 sobre avaliação de riscos, são os seguintes:

Quadro 01 - Casos na OMC 29

\begin{tabular}{|c|c|}
\hline Artigo & Casos \\
\hline 5.1 & $\begin{array}{c}\text { DS203, FD245, DS270, DS284, DS287, } \\
\text { DS291, DS292, DS293, DS367, DS389, } \\
\text { DS391, DS392, DS430, DS447, DS448, } \\
\text { DS475, DS484 }\end{array}$ \\
\hline 5.2 & $\begin{array}{l}\text { DS245, DS270, DS291, DS292, DS293, } \\
\text { DS297, DS367, DS389, DS392, DS430, } \\
\text { DS448, DS475, DS484 }\end{array}$ \\
\hline 5.3 & $\begin{array}{c}\text { DS245, DS270, DS297, DS367, DS392, } \\
\text { DS475 }\end{array}$ \\
\hline
\end{tabular}

Fonte: Elaborado pelo autor com dados extraídos de OMC (2016)

Ao analisarmos as disputas sob o artigo 5 do SPS, vemos que ao se tratar de risco, os parágrafos de referência utilizados nas demandas pelos painéis são pelo menos dois para a caracterização da situação envolvida na maioria dos casos estudados. Nos 17 casos ocorridos no período analisado houveram 11 Estados reclamantes, estando entre eles sete Estados em desenvolvimento. O Estado que mais estabeleceu disputas sobre os referidos artigos em estudo foram os Estados Unidos, o qual foi reclamante em cinco painéis sobre produtos de origem animal, vegetal e biotecnológicos. O Brasil abriu somente uma disputa nesse tema, no ano de 2014 contra a Indonésia a respeito de medidas relativas a importação de carne e produtos de frango.

Entre os Estados que estariam infligindo os artigos do SPS de modo a serem demandados na OMC, estão apenas 10 Estados (considerando a Comunidade Europeia como somente um ator). A Comunidade Europeia e os Estados Unidos foram

29. O título de cada caso e partes envolvidas se encontram na tabela 02 . 
alvo de um terço das disputas estabelecidas, podendo entáo serem vistos como os que mais apontam riscos nos produtos importados, criando barreiras comerciais e causando questionamento por parte dos Estados exportadores desses produtos. Nos casos demandando esses dois atores, pode-se observar como demandantes Estados em desenvolvimento, com exceção de duas disputas contra a Comunidade Europeia onde Estados Unidos e Canadá também foram demandantes.

Além dos Estados que constam como demandantes nos casos em estudo, outros Estados em desenvolvimento participaram nas disputas como terceira parte ${ }^{30}$. Nos casos listados na tabela 02 houve a participação de 32 Estados $^{31}$ diferentes como terceiras partes, sendo 25 Estados em desenvolvimento ${ }^{32}$. Vale ainda ressaltar que os casos DS 448 - sobre importaçẫo de limóes argentinos, DS 297 - importação de animais vivos e produtos de carne da Hungria, DS 284 - importação de feijốes pretos da Nicarágua e DS 203 - comercialização de suínos provenientes dos Estados Unidos, apresentaram questôes específicas dos Estados demandantes, não tendo assim outros Estados participando como terceiras partes.

$\mathrm{Na}$ grande maioria dos casos pode-se observar que o Estado importador também é produtor daquele produto para o qual foi imposto algum tipo de barreira sanitária ou fitosanitária. Entre os Estados demandantes encontram-se grandes produtores mundiais, como nos casos das carnes e animais vivos, os quais estão também entre os maiores ex-

30. Os Estados que concordem com a demanda realizada podem participar da disputa como terceira parte não precisando apresentar nova demanda à OMC.

31. A União Europeia e Comunidade Europeia foram consideradas como um ator para efeito de contagem do número de atores diferentes atuando como terceira parte nos casos em estudo.

32. OS Estados participantes como terceira parte foram: Argentina, Austrália, Brasil, Chile, China, Colômbia, Coreia, Coreia do Sul, El Salvador, Equador, Filipinas, Guatemala, Honduras, Índia, México, Paquistão, Paraguai, Peru, República Dominicana, Rússia, Tailândia, Taipei, Turquia, Uruguai, Vietnã. portadores. A partir da análise dos casos infere-se que existe certa imposição de restriçâao baseada nos fatores de risco não comprovados pelos Estados demandados (principal ponto de questionamento pelos Estados demandantes), a qual estaria relacionada a uma defesa do comércio interno frente à importação daquele determinado produto proveniente de um grande competidor externo como se observa nos casos de comercialização de carne suína e de frango principalmente.

Partindo da característica comercial dos Estados exportadores, pode-se concluir que as imposições de barreiras baseadas no risco teriam duas implicações: o risco para a população do Estado importador, podendo ser disseminado a um grande número de pessoas devido aos altos volumes de importação; e o risco sendo usado como barreira comercial para impedir o grande volume de importaçóes.

A partir da análise do status das disputas estabelecidas no âmbito da OMC, observa-se que a grande maioria alcançou uma solução acordada pelas partes. E em apenas um caso houve a requisição de retaliação por parte do Estado que sofreu a suspensão de vendas ao Estado de destino a partir da alegação de riscos, que foi o caso dos Estados Unidos em 2003, que sofreu medidas que afetaram a aprovação e comercialização de produtos biotecnológicos na Europa.

Nos casos resolvidos sem o estabelecimento ou discussão através de painel, o DS 391 - sobre importação de carne bovina, a Coreia concordou com a indicação do Canadá, e os dois chegaram a um acordo. E nos casos DS 297 - Hungria e Croácia sobre a importação de animais vivos e produtos de carne, DS 284 - Nicarágua reclamando das restriçôes mexicanas para importação de feijốes pretos, as requisiçôes foram atendidas em consequência de negociaçôes. Isso demonstra que as medidas adotadas pelos Estados reclamados não eram adequadas e extrapolavam a necessidade de contenção de riscos. 
Quadro 02 - Casos na OMC envolvendo a questão dos riscos e o acordo SPS

\begin{tabular}{|c|c|c|c|c|c|}
\hline $\begin{array}{l}\text { Número } \\
\text { do caso }\end{array}$ & Reclamado & Caso & Reclamante & Data & Status \\
\hline DS484 & Indonésia & $\begin{array}{l}\text { Medidas relativas a importação de carne } \\
\text { de frango e produtos de frango }\end{array}$ & Brasil & 2014 & Em consulta \\
\hline DS457 & Rússia & $\begin{array}{l}\text { Medidas para importação de porcos vivos } \\
\text { e outros produtos de suínos da União } \\
\text { Europeia }\end{array}$ & $\begin{array}{l}\text { União } \\
\text { Européia }\end{array}$ & 2014 & $\begin{array}{l}\text { Painel } \\
\text { composto }\end{array}$ \\
\hline DS448 & $\begin{array}{l}\text { Estados Uni- } \\
\text { dos }\end{array}$ & $\begin{array}{l}\text { Medidas afetando a importaçáo de } \\
\text { limóes frescos }\end{array}$ & Argentina & 2012 & Em consulta \\
\hline DS447 & $\begin{array}{l}\text { Estados Uni- } \\
\quad \text { dos }\end{array}$ & $\begin{array}{l}\text { Medidas afetando a importação de ani- } \\
\text { mais, carne e outros produtos animais da } \\
\text { Argentina }\end{array}$ & Argentina & 2012 & Painel composto \\
\hline DS430 & Índia & $\begin{array}{l}\text { Medidas concernentes a importaçáo de } \\
\text { certos produtos agrícolas dos Estados } \\
\text { Unidos }\end{array}$ & $\begin{array}{l}\text { Estados } \\
\text { Unidos }\end{array}$ & 2012 & $\begin{array}{l}\text { Relatório do painel } \\
\text { sob apelação }\end{array}$ \\
\hline DS392 & $\begin{array}{l}\text { Estados Uni- } \\
\quad \text { dos }\end{array}$ & $\begin{array}{l}\text { Certas medidas afetando a importação } \\
\text { de frango da China }\end{array}$ & China & 2009 & $\begin{array}{c}\text { Relatórios adotados } \\
\text { sem outras açóes } \\
\text { requisitadas }\end{array}$ \\
\hline DS391 & $\begin{array}{l}\text { República da } \\
\text { Coréia }\end{array}$ & $\begin{array}{l}\text { Medidas afetando a importação de carne } \\
\text { bovina e produtos de carne do Canadá }\end{array}$ & Canadá & 2009 & $\begin{array}{c}\text { Solução } \\
\text { acordada }\end{array}$ \\
\hline DS389 & $\begin{array}{l}\text { Comunidades } \\
\text { Europeias }\end{array}$ & $\begin{array}{l}\text { Certas medidas afetando carne de frango } \\
\text { e produtos de frango dos Estados Unidos }\end{array}$ & $\begin{array}{l}\text { Estados } \\
\text { Unidos }\end{array}$ & 2009 & $\begin{array}{l}\text { Estabelecimento de } \\
\text { painel, mas ainda } \\
\text { não composto }\end{array}$ \\
\hline DS367 & Austrália & $\begin{array}{l}\text { Medidas afetando a importação de } \\
\text { maçás da Nova Zelândia }\end{array}$ & $\begin{array}{l}\text { Nova Zelân- } \\
\text { dia }\end{array}$ & 2007 & $\begin{array}{c}\text { Implementação } \\
\text { notificada pelo re- } \\
\text { spondente }\end{array}$ \\
\hline DS297 & Croácia & $\begin{array}{l}\text { Medidas afetando a importação de ani- } \\
\text { mais vivos e produtos de carne }\end{array}$ & Hungria & 2003 & $\begin{array}{l}\text { Resolvido ou termi- } \\
\text { nado (solução mutu- } \\
\text { amente acordada) }\end{array}$ \\
\hline DS293 & $\begin{array}{l}\text { Comunidades } \\
\text { Europeias }\end{array}$ & $\begin{array}{l}\text { Medidas afetando a aprovação e comer- } \\
\text { cializaçáo de produtos biotecnológicos }\end{array}$ & Argentina & 2003 & $\begin{array}{l}\text { Resolvido ou termi- } \\
\text { nado (soluçáo mutu- } \\
\text { amente acordada) }\end{array}$ \\
\hline DS292 & $\begin{array}{l}\text { Comunidades } \\
\text { Europeias }\end{array}$ & $\begin{array}{l}\text { Medidas afetando a aprovação e comer- } \\
\text { cialização de produtos biotecnológicos }\end{array}$ & Canadá & 2003 & $\begin{array}{l}\text { Resolvido ou termi- } \\
\text { nado (soluçáo mutu- } \\
\text { amente acordada) }\end{array}$ \\
\hline DS291 & $\begin{array}{l}\text { Comunidades } \\
\text { Europeias }\end{array}$ & $\begin{array}{l}\text { Medidas afetando a aprovação e comer- } \\
\text { cialização de produtos biotecnológicos }\end{array}$ & $\begin{array}{l}\text { Estados } \\
\text { Unidos }\end{array}$ & 2003 & $\begin{array}{l}\text { Requisição de } \\
\text { autorizaçâo para } \\
\text { retaliaçáo (incluindo } \\
\text { arbitragem 22.6) }\end{array}$ \\
\hline DS287 & Austrália & Regime de quarentena para importaçóes & $\begin{array}{l}\text { Comuni- } \\
\text { dade Euro- } \\
\text { peia }\end{array}$ & 2003 & $\begin{array}{l}\text { Resolvido ou termi- } \\
\text { nado (soluçáo mutu- } \\
\text { amente acordada) }\end{array}$ \\
\hline DS284 & México & $\begin{array}{l}\text { Certas medidas impedindo a importação } \\
\text { de feijóes pretos da Nicarágua }\end{array}$ & Nicaraguá & 2003 & $\begin{array}{l}\text { Resolvido ou termi- } \\
\text { nado (soluçáo mutu- } \\
\text { amente acordada) }\end{array}$ \\
\hline DS270 & Austrália & $\begin{array}{l}\text { Certas medidas impedindo a importaçáo } \\
\text { de frutas frescas e vegetais }\end{array}$ & Filipinas & 2002 & $\begin{array}{l}\text { Painel estabelecido, } \\
\text { mas ainda não com- } \\
\text { posto }\end{array}$ \\
\hline DS245 & Japão & $\begin{array}{l}\text { Medidas afetando a importação de } \\
\text { maçás }\end{array}$ & $\begin{array}{l}\text { Estados } \\
\text { Unidos }\end{array}$ & 2002 & $\begin{array}{l}\text { Resolvido ou termi- } \\
\text { nado (solução mutu- } \\
\text { amente acordada) }\end{array}$ \\
\hline DS2003 & México & $\begin{array}{l}\text { Medidas afetando a comercialização de } \\
\text { suínos vivos }\end{array}$ & $\begin{array}{l}\text { Estados } \\
\text { Unidos }\end{array}$ & 2000 & Em consulta \\
\hline
\end{tabular}


Para se chegar a uma solução nos outros casos, foi necessário o estabelecimento de um painel, tendo os seguintes resultados:

- DS 293 - Argentina contra Comunidade Europeia - acordo após o painel, e estabelecimento de diálogo sobre a aplicação de biotecnologia para a agricultura;

- DS 292 - Canada contra Comunidade Europeia - o painel concluiu que a Comunidade Europeia não agiu em desacordo com os artigos do acordo SPS, mas somente em desacordo ao anexo $\mathrm{C}$ - sobre procedimentos de controle, inspeção e aprovação, artigo 1 do SPS; houve entáo acordo entre as partes e estabelecimento de diálogo sobre o mercado de biotecnologia agrícola;

- DS 297 - Comunidade Europeia contra Austrália - após o painel, houve acordo sobre transparência do regime de quarentena australiano, princípios de acesso a mercado, e discussóes estre especialistas sobre aspectos científicos do comércio de carnes.

Entre os painéis estabelecidos, destaca-se o caso DS 245 sobre a importação de maçãs entre Estados Unidos e Japão no qual foi estabelecido a definição de risco desprezível, como aquele cuja probabilidade de ocorrência é muito pequena. Neste caso, segundo Gruszczynski (2008), a medida fitossanitária foi desproporcional ao risco identificado e a evidência científica presente. Assim, não teria existido uma relação racional ou objetiva entre a evidência científica e a medida aplicada. O caso DS 245 terminou com uma solução acordada entre as partes.

$\mathrm{Na}$ conclusão dos painéis houve sempre uma indicaçấo da necessidade de diálogo e desenvolvimento científico entre as partes envolvidas para que as questóes levantadas pudessem ser melhor estudadas e avaliadas. Isso demonstra que as medidas adotadas foram superiores ao risco conhecido por falta de informação sobre o risco real, ou sobre as ativi- dades aplicadas pelo outro Estado. Shaffer (2008) ainda indica que a regulação adotada sem a análise científica sugere a prática de protecionismo, e que na maioria dos casos é uma regulação discriminatória. O custo derivado de uma medida como essa é arcada pelo Estado que a impóe, pois ele somente muda a política após o manifesto do Estado exportador em alguma arena, como no órgão de solução de controvérsias da OMC que gera uma negociação ou determinação de conduta.

\section{Considerações finais}

As normas da Organização Mundial do Comércio e de outros organismos internacionais que tratam da questão do risco refletem a preocupaçáo dessas organizaçóes com a integridade das pessoas ou do meio em que pode haver consequências pela produção, consumo, uso ou propagação de determinada substância. Essas normas surgem para estabelecer algum nível de controle sobre a tomada de decisão dos agentes que desenvolvem novas tecnologias para a maximização da produtividade ou eficácia de algum processo. Em relação a isso, Beck trata do dilema da política tecnológica ${ }^{33}$, na qual as decisóes sobre o avanço tecnológico seriam pautadas no lucro das empresas e seus investimentos e consequentemente as vagas de emprego. A partir disso, os riscos em decorrência de alguma ação ou uso de alguma substância não seria considerado de maneira apropriada, visto a finalidade econômica das atividades.

A economia seria então um objetivo, e Beck fala então em dupla limitação:

[...]de um lado, estimativas de efeitos colaterais têm lugar sob a pressão das decisōes de investimento tomadas a reboque da incumbência da rentabilidade. De outro lado, isto é aliviado pelos efeitos que são de qualquer maneira difíceis de estimar, enquanto, por outro

33. BECK, 2010, p.312. 
lado, contramedidas do Estado demandam longos caminhos e prazos para serem implementadas. (BECK, 2010, p. 313)

Em decorrência disso, problemas seriam criados para a sociedade. Essas medidas estariam pautadas no progresso, o que justificaria a atuação e os efeitos colaterais na sociedade, pois seriam necessários para o alcance do objetivo "progresso".

Teóricos que tratam do tema riscos, como Beck, afirmam que os Estados em desenvolvimento sofrem com riscos, e em movimento contrário, no âmbito do comércio internacional, há a presença de barreiras comerciais aos produtos provenientes desses Estados a partir da presunção de algum tipo de risco. Apesar dessa ser a maior ocorrência em disputas no âmbito da Organização Mundial do Comércio, também pode-se observar que no intercâmbio entre Estados de mesmo nível de desenvolvimento, o argumento da presença do risco é utilizado. O que é preciso ser analisado mais detalhadamente é se esses riscos apontados realmente existiram ou se foram levantados somente como uma barreira comercial para o cenário daquele momento, já que algumas disputas não chegaram a ter o relatório final do painel por terem sido concluídas por acordos entre as partes. Os riscos devem ser apontados com base em evidência científica e não somente como item de protecionismo. Assim, o órgão de solução de controvérsias deveria exigir a avaliação dos riscos a partir de estudos científicos para todos os casos.

No contexto do Acordo de Medidas Sanitárias e Fitossanitárias da OMC a inclusão do tema risco é de suma importância ao se tratar da comercialização dos produtos que estão sob este tema, e pode-se observar que ao longo da existência da organização o tema foi apontado em diversas disputas, demonstrando sua influência para as transaçóes comerciais. O uso do Acordo para a suspensão de importaçóes levou a discussão sobre a pertinência ou não da suspeição sobre o risco e da aplicabilidade de medidas sanitárias ou fitosanitárias. A imposição desse tipo de sanção momentânea se deu não somente entre Estados de diferentes níveis de desenvolvimento, mas principalmente entre Estados concorrentes na produção e comercialização dos produtos afetados pelas medidas.

\section{Referências}

ADAM, Barbara; LOON, Joost Van. Introduction: repositioning risk; the challenge for social theory. In: ADAM, Barbara; BECK, Ulrich; VAN LOON, Joost. (Ed.) The risk society and beyond: critical issues for social theory. London: SAGE, 2000.

ATA final que incorpora os resultados das negociaçóes comerciais multilaterais da Rodada Uruguai. Marraqueche: Planalto, 1994. Disponível em : <http://www.planalto.gov.br/ccivil_03/ decreto/1990-1994/anexo/and1355-94.pdf>. Acesso em: 27 out. 2016.

BECK, Ulrich. A sociedade de risco: rumo a uma outra modernidade. São Paulo: Ed. 34, 2010.

BRASIL. Ministério do Meio Ambiente. Declaração do rio sobre meio ambiente e desenvolvimento. Brasília: MMA, 1992. Disponível em: <http://www.mma.gov.br/port/sdi/ea/documentos/convs/decl_rio92.pdf. . Acesso em: 26 out. 2016.

Codex Alimentarius. Procedural Manual. Disponível em: $<$ http://www.fao.org/fao-who-codexalimentarius/procedures-strategies/procedural-manual/en/>. Acesso em: 20 out. 2016.

GOLDSTEIN, Bernard; CARRUTH, Russellyn S. The precautionary principle and/or risk assessment in World Trade Organization decisions: a possible role for risk perception. Risk Analysis, v. 24, n. 2, 2004.

GRUSZCZYNSKI, Lukasz. Risk management policies under the WTO agreement on the application of sanitary and phytosanitary measures. Asian Journal of WTO \& international health law and policy, v.3, n. 1, p. 261-308, 2008.

GUZMAN, Andrew. Dispute resolution in SPS cases. In: HOROVITZ, Dan, et al. Ten years of WTO dispute settlement. London: International Bar Association, 2007.

JACKSON, John Howard. The world trading system: law and policy of international economic relations. $2^{\text {nd }}$ edition. Cambridge: MIT Press, 2002.

KAYE, Tim. Law and risk: an introduction. In: WOODMAN, Gordon; KLIPPEL, Diethelm. Risk and the law. London: Routledge, 2008.

O'MALLEY, Pat. Governmentality and risk. Sydney: The University of Sydney, Sydney law school. 2009.

Organização Mundial para Saúde Animal. Disponível em: $<$ http://www.oie.int/about-us/our-missions/> 
PRAZERES, Tatiana L. Comércio internacional e protecionismo: as barreiras técnicas na OMC. São Paulo: Aduaneiras, 2003.

SECRETARIAT OF THE INTERNATIONAL PLANT PROTECTION CONVENTION. International Plant Protection Convention. [S.1.]: FAO, 1997. Disponível em: <https://www.ippc.int/static/media/files/publications/ en/2013/06/06/1329129099_ippc_2011-12-01_reformatted. pdf $\geq$. Acesso em: 27 out. 2007.

SHAFFER, Gregory. A structural theory of WTO dispute settlement: why institutional choice lies at the center of the GMO case. New York University Journal of International Law and Politics, 2008.

STOLL, Peter Tobias; SCHORKOPF, Frank. WTO: World Economic Order, World Trade Law. Boston: Martinus Nijhoff Publishers, 2006.

WORLD HEALTH ORGANIZATION; FOOD AND AGRICULTURE ORGANIZATION OF THE UNITED NATIONS. Codex alimentarius commission: procedural manual, 23rd th edition. Rome: WHO; FAO, 2015.

WORLD TRADE ORGANIZATION. DS 245: Japan: measures affecting the importation of apples. United States: WTO, 2005. Disponível em: <https://www.wto.org/english/tratop_e/ dispu_e/cases_e/ds245_e.htm>.Acesso em: 27 out. 2016.

WORLD TRADE ORGANIZATION. DS 284: Mexico: certain measures preventing the importation of black beans from Nicaragua. Nicaragua: WTO, 2004. Disponível em: <https:// www.wto.org/english/tratop_e/dispu_e/cases_e/ds284_e. htm $\geq$. Acesso em: 27 out. 2016.

WORLD TRADE ORGANIZATION. DS 287: Australia: quarantine regime for imports. Australia: WTO, 2007. Disponível em: <https://www.wto.org/english/tratop_e/dispu_e/ cases_e/ds287_e.htm>. Acesso em: 27 out. 2016.

WORLD TRADE ORGANIZATION. DS 292: European Communities: measures affecting the approval and marketing of biotech products. Canada: WTO, 2009. Disponível em: <https://www.wto.org/english/tratop_e/dispu_e/cases_e/ ds292_e.htm>. Acesso em: 27 out. 2016.

WORLD TRADE ORGANIZATION. DS 293: European Communities: measures affecting the approval and marketing of biotech products. Argentina: WTO, 2010. Disponível em: <https:/www.wto.org/english/tratop_e/dispu_e/cases_e/ ds293_e.htm>. Acesso em: 27 out. 2016.

WORLD TRADE ORGANIZATION. DS 297: Croatia: measures affecting imports of live animals and meat products. Hungary: WTO, 2009. Disponível em:<https://www.wto.org/english/tratop_e/dispu_e/cases_e/ds297_e.htm>. Acesso em: 27 out. 2016.

WORLD TRADE ORGANIZATION. DS 389: European Communities: certain measures affecting poultry meat and poultry meat products from the United States. United States: WTO, 2009. Disponível em: <https://www.wto.org/english/tratop_e/ dispu_e/cases_e/ds389_e.htm>. Acesso em: 27 out. 2016.
WORLD TRADE ORGANIZATION. DS 391: Korea: Measures affecting the importation of bovine meat and meat products from Canada. Canada: WTO, 2012. Disponível em: <https://www.wto.org/english/tratop_e/dispu_e/cases_e/ ds391_e.htm>. Acesso em: 27 out. 2016.

WORLD TRADE ORGANIZATION. The WTO agreement on the application of sanitary and phytosanitary measures (SPS Agreement). [S.1.]: WTO, 2016. Disponível em: <https://www.wto.org/english/tratop_e/sps_e/spsagr_e.htm>. Acesso em: 20 out. 2016>.

Organização para a alimentação e agricultura - FAO, Disponível em: <http://www.fao.org>.

WORLD TRADE ORGANIZATION. Uruguay round agrément: understanding on rules and procedures governing the settlement of disputes. [S.I]: WTO, 2016. Disponível em: <https://www.wto.org/english/docs_e/legal_e/28-dsu_e.htm>. Acesso em: 27 out. 2016. 